On Implementation of Classroom-Based Pedagogies of Engagement: Relevant Measures and General Outcomes

Dr. Waddah Akili, Iowa State University

Waddah Akili is an academician and a civil engineering consultant in Ames, Iowa. Has published in various fields including: geotechnical engineering, foundations, and pavement materials \& design. He has been involved with contemporary engineering education issues, addressing a wide range of topics of interest and relevance to engineering institutions and practicing engineers, in the US and abroad. 


\title{
On Implementation of Classroom-Based Pedagogies of Engagement: Relevant Measures and General Outcomes
}

\begin{abstract}
Educators, at all levels, as well as policy planners have advocated student involvement as an essential aspect of meaningful learning. Learning "about” things through conventional methods (low interaction lecture-based) does not necessarily enable students to acquire the abilities and understanding they will need for their future studies and or careers. Research has shown that interaction among students and interaction between faculty and students- carried by far the largest weights and affected more general education outcomes than any other factor examined, including the curriculum content factors. The paper focuses on implementation of problem-based learning (PBL) in an engineering program, examines different variations of PBL discussed in the literature, selects suitable versions for potential adoption at the start, and identifies and illustrates faculty role in implementing PBL. It also includes a brief history of PBL, selected strategies to infuse PBL in an engineering program, and suggestions for redesigning courses to catalyze change in the classroom environment through student engagement. The paper, also, addresses the potential difficulties that could arise during implementation of PBL, particularly when instructors are new to this instructional method, and argues for the need, at the start, to resort to "informal” cooperative learning approaches, intertwined with the traditional lecture, to help equip students with the tools necessary for the formation of long-term cooperative learning strategies, enabling students to acquire the knowledge and understanding they will need for their future careers.
\end{abstract}

\section{Introduction}

Achieving change via engineering education reform is a formidable challenge to any college of engineering, whether in North America or anywhere else in the world. In the past two decades engineering educators have tried to implement relatively new methodologies in the classroom, primarily characterized by students' active engagement or involvement in his or her academic work, resulting in better retention of new knowledge and acquisition of desirable personal traits. Any such method that engages students in the learning process is labeled as: "active learning" method. In essence, active learning requires doing meaningful learning activities in groups under the guidance of an informed and experienced teacher. As stated by Christensen et al ${ }^{(1)}$, "To teach is to engage students in learning." The main point is that engaging students in learning is principally the responsibility of the teacher, who becomes less an imparter of knowledge and more a designer and a facilitator of learning experiences and opportunities. In other words, the real challenge in college teaching today is not covering the material for the students, but rather uncovering the material with the students. ${ }^{(2)}$

There are several strands of pedagogies of engagement under the umbrella of active learning methods that have received attention by engineering educators world-wide. ${ }^{(2,3)}$ For many faculty, there remain questions about what "active learning" is and how it differs from traditional 
engineering education, since the latter involves activities through homework assignment, laboratories, and, often, group projects. Adding to the confusion, engineering faculty do not always understand how the common forms of "active learning" differ from each other and most are not inclined to search for answers. Of the most known and utilized classroom-based pedagogies in engineering education today, and appear to be moving in the same broad direction, are: problem-based learning (PBL), cooperative learning, and collaborative learning. ${ }^{(2)}$

Problem-based learning (PBL) starts when students are confronted with an open-ended, illstructured, real-world problem and work in teams to identify learning needs and develop a viable solution, with instructors acting as facilitators rather than primary sources of information. ${ }^{(3)}$ There are numerous PBL teaching models, and are all equally valid and appear to work depending on factors and prevailing circumstances such as: 1) characteristics and orientation of the curriculum, 2) attitudes, knowledge, and skills of the academic staff, 3) underpinning academic culture of teaching and learning, and, 4) socio-economic background and abilities of the student body. ${ }^{(2,3,4)}$ The paper examines different variations of PBL discussed in the literature, selects suitable versions for potential adoption at the start, identifies essential elements of a well-structured learning strategy, and illustrates faculty role in implementing PBL.

Proven methodologies and knowledge generated elsewhere, if and when properly adapted, should make it possible for institutions to devise their own PBL models that meet their classroom setting, objectives, and aspirations. The paper sheds light on the nature of such models and argues for the need to conduct research in order to guide the process of transition from the old to the new paradigm, to ensure the vitality and currency of engineering education.

\section{Active Learning: Definitions and Interpretations}

It is difficult to come to grip with all the cited definitions, meanings, and interpretations of the term "active learning", since different contributors in the field have interpreted some terms differently. However, by gleaming at the literature, it is possible to arrive at general consensus of what appears to be widely accepted definitions, and to shed light on how common terms are used.

Active learning is generally defined as any instructional method that engages students in the learning process. It is widely accepted that active learning requires students to take part in "preplanned" learning-related activities, believed to spark and stimulate their learning, while in the classroom. ${ }^{(5,6)}$ These activities would include: reading, writing, solving problems, answering questions, participating in a discussion, etc.; and most important, students must be engaged in thinking tasks while actively involved. It is generally understood that during active learning, less emphasis is placed on transmission of information and more on developing students' skills. Additionally, during an active learning cycle, emphasis is placed on students' exploration of their own abilities, including: their thinking process, their value system, their intellect, and their courage to express themselves orally and in writing. Active learning is contrasted to the traditional lecture where students passively receive information from the instructor. ${ }^{(6,7,8)}$

Collaborative learning refers to any and all of the instructional methods where students work together in small groups towards a common goal. ${ }^{(2,3)}$ It can be viewed as encompassing all group-based instructional methods, including cooperative learning. ${ }^{(3,8,9)}$ The central element of 
collaborative learning is collaboration vs. individual work. ${ }^{(3)}$ A number of meta-analysis supports the view that collaboration does promote a broad range of student learning outcomes. In particular, collaboration enhances academic achievement, and student attitudes. It also reduces student attrition. ${ }^{(3)}$

Cooperative learning is a formalized active learning structure where students work together in small groups to accomplish shared learning goals and to maximize their own and each others learning. The most common model of cooperative learning in engineering is that of Johnson, Johnson and Smith. ${ }^{(10)}$ This model has five specific elements: mutual interdependence, individual accountability, face to face interaction, interpersonal and small group skills, and individual assessment of group functioning. ${ }^{(10)}$ Although different cooperative models exist ${ }^{(10 \text {, }}$ ${ }^{11)}$, the core element in all of these models is the emphasis on cooperative incentives rather than competition in the promotion of learning. Some researchers view cooperative and collaborative learning as having two distinct historical developments and differing philosophical roots. ${ }^{(12)}$ .Despite differences and similarity of the two approaches (collaborative vs. cooperative), the fact remains that the core element of both, is the emphasis on student interactions as the primary source of learning, rather than learning as individuals.

Problem-based learning (PBL) is an instructional method where relevant problems are introduced during the course to provide the context and motivation for the learning that follows. ${ }^{(13)} \mathrm{PBL}$, by and large, is self-directed learning that helps develop positive student attitudes, fosters a deeper approach to learning, and helps students retain knowledge longer than traditional instruction. It is appropriate here to mention that several approaches go under the name of problem-based-learning. These known approaches to PBL have as many differences as they have elements in common, making interpretation of outcome rather difficult. ${ }^{(14)}$

Before adopting a specific method of active learning, faculty members need to become familiar with the literature and, in particular, the various strategies that promote active learning in the classroom. Despite familiarity with the literature, ambiguity and confusion may result, at times, from reading the literature; particularly when the effectiveness of any instructional method is examined and /or compared with another method. Assessing "what works" requires looking at a broad range of learning outcomes, interpreting results carefully, and quantifying the magnitude of any reported improvement. To assess critically "what works" for a given set of conditions, the reader has to attain sufficient knowledge and familiarity with the subject matter. ${ }^{(2,3)}$

Reported studies, by and large, tell us about success stories and seldom reveal what has not worked. Irrespective of how data, results, and interpretations are presented in the literature, faculty adopting a specific method with the expectations of experiencing similar results to those in the literature, should be aware of the limitations of any reported piece of research, i.e., such reports may not reveal all factors and details; and therefore, extrapolating without a thorough investigation could be misleading. This should not, by any means, discourage faculty from moving toward active learning; but rather intended as a "precautionary" observation, to new instructors: Not "to make too much" out of what they have read unless it is credible, thorough, and substantiated with facts and figures. Despite some pitfalls, engineering faculty should be strongly encouraged to examine the literature on active learning, including: the empirical research on its use, and the common barriers that may arise as a consequence of its application. 
Problem-based learning (PBL) is one of the learning strategies that are based on student center learning, and is gaining momentum worldwide. The author believes that learning "about" things is not enough to enable students to acquire the skills and abilities they will need in the future. Rather pedagogies of engagement such as PBL, if and when properly implemented, will turn out the kinds of resourceful, engaged professionals that engineering practice does need. In the sections that follow, the author presents: i) relevant information on PBL, its practices and working models; ii) cooperative learning as a priori to PBL ; and, iii) the lecture format, if and when combined with a selected active learning strategy, such as PBL, and its potential utilization in a traditional classroom setting.

\section{Problem-Based Learning: Historical Origin, Precepts, Practices, and Working Models}

The modern history of problem-based learning begins in the early 1970s at the medical school at McMaster University in Canada. Its intellectual history is far older. Thomas Corts, president of Samford University, sees PBL as "a newly recovered style of learning". In his view; it embraces the question-and-answer dialectical approach associated with Socrates as well as the Hegelian thesis-antithesis-synthesis dialectic. ${ }^{(15)}$ As John Cavanaugh puts it: "It's like discovery-based learning in the 1960s. We knew about it; we didn't do it.” ${ }^{(15)}$ Until recently, the PBL approach has flourished mainly in medical and professional schools. Slowly the sciences in general, have begun taking it up, and even more slowly, the humanities. PBL does not have a store of transferable techniques or methods like cooperative learning, no "jigsaw," no "think-pair-share" or that sort of thing. Opinions vary on whether PBL should be implemented for entire courses or whether it can be used merely to teach certain parts of courses. In general, advocates accept faculty easing into the approach piecemeal, but favor course-long continuity. ${ }^{(15)}$

In some ways what PBL is, seems self-evident: It's learning that results from working with problems. Official descriptions generally describe it as "an instructional strategy in which students confront contextualized, ill-structured problems and strive to find meaningful solutions.” (15) In other words, in PBL, learning results from the process of working toward the understanding or resolution of a problem. The problem is encountered first in the learning process. ${ }^{(16)}$ Barrows identifies six core features of PBL ${ }^{(17)}$. These features are: i) Learning is student-centered. ii) Learning is best accomplished in small groups. iii) Problems are the main focus and stimulus for learning. iv) Problems are the vehicle for the development and acquisition of problem-solving skills. v) Teachers are primarily facilitators of learning. And, vI) New information is acquired through self-directed learning.

The list of reasons for the deployment of PBL includes the fact that problem-based learning ends up orienting students toward meaning-making over fact-collecting. Students learn via contextualized problem sets and situations. Because of that, and all that goes with it, namely the dynamics of group work and independent investigation, they achieve higher levels of comprehension, develop more learning and knowledge-forming skills and more social skills as well. This approach to teaching brings prior knowledge into play more rapidly and ends up fostering learning that adapts to new situations and related domains quickly and effectively. According to Woods ${ }^{(18)}$, PBL is suitable for introductory sciences and engineering classes -as it is for medicine- because it helps students develop skills and confidence for formulating problems they have never seen before. The largest scale implementation of PBL in the USA at the undergraduate level has been at the University of Delaware, where it has been used for many 
courses including courses in science and engineering. ${ }^{(19)}$ Woods at McMaster University has described the university implementation of PBL in engineering. According to Woods, PBL is used widely in junior and senior levels in the civil and chemical engineering programs at McMaster. ${ }^{(18)}$

But where does PBL fit compared with all the other "learning methods"? Faculty hear about-"cooperative learning," "collaborative learning," and "active learning". The proliferation of "learnings" and their attendant partisan camps invites the reawakening of long-standing faculty prejudice against educational fads and "methods." Even so, interest in PBL grows because not only does research show a higher quality of learning (though not a greater amount if "amount" equates with the number of facts), but problem-based learning simply feels right intuitively. It seems to reflect the way the mind actually works. ${ }^{(15)}$ Unfortunately, while there is agreement on the general definition of PBL, implementation has varied widely. ${ }^{(3)}$ The large variation in PBL practices makes the analysis of its effectiveness a bit complex. Many studies comparing PBL to traditional programs are simply not talking about the same thing. As reported by Prince (3), “ For meta-studies of PBL, to show any significant effect compared to traditional programs, the signal from the common elements of PBL would have to be greater than the noise produced by differences in the implementation of both PBL and traditional curricula.” Despite this, there are positive findings that do emerge from the literature, which support the following: i) PBL produces positive student attitudes, ii) PBL does provide more challenging, motivating and enjoyable approach to education, iii) PBL improves the long-term retention of knowledge compared to traditional instruction, and iv) PBL promotes deep learning and problem-solving skills.

A. Essentials of PBL: Problem-based learning is a philosophy that has to be adapted to the specific conditions and situation of an institution, and the nature of the specific field in which it is to be implemented. This is apparent in the different models of PBL implementation through out the world. Therefore, there is no one-size-fits-all approach to PBL that can simply be implemented from one institution to another. ${ }^{(20)}$ There are essential and required steps that have to be mobilized at the start of PBL. At the start of learning in PBL is the selection of real problem(s). This is, in fact, the major driving force for learning. Effort and time dedicated to the selection of problem(s), is time well-spent and will eventually pay off. The problem(s) should be well crafted to engage and immerse students in learning new materials, new issues, as well as challenging existing knowledge, skills, and attitudes. It is important to note that PBL is not only about giving problems and solving them in classroom, but it is also about creating opportunities for students to construct knowledge through interactions and collaborative inquiry. ${ }^{(20)}$

In PBL, the instructor is primarily a facilitator, whose role is to make the learning process visible, instead of making the content visible as in traditional lectures. Since assessment drives learning, the modes of assessment must also be modified to appropriately evaluate students for the desired outcomes that have been designed for the problem. For students to become problem solvers, they have to be actively involved in the learning process. When students are exposed to PBL for the first time, they must be guided, prepared, and motivated. It is not fair to expect students to readily have the skills for PBL, particularly when they have been exposed solely to traditional classroom environment. Therefore students need to be prepared by exposing them to informal cooperative learning, where students are to work together to achieve a joint learning goal in temporary, ad-hoc groups, that may last from a few minutes to one class period. ${ }^{(21)}$ 
Informal cooperative learning groups also ensure that misconceptions, incorrect understanding, and gaps in understanding are identified and corrected. Using procedures such as informal cooperative learning guarantees that students have been exposed to some active and interactive methods prior to engaging in PBL.

B. Infusing PBL in the Curriculum: There are several strategies that may be utilized to infuse PBL in an engineering curriculum. The selected strategy depends upon: 1) the commitment of the institution, as a whole, to the process of deploying active learning schemes in general, and PBL in particular, 2) the readiness of the teaching staff, and 3) available recourses, facilities, and support services. Table 1 illustrates three approaches to infuse PBL in the curriculum as suggested by Tan at the mega, macro and micro levels. ${ }^{(20)}$ Implementing PBL at the mega level requires commitment from the administration as well as from the teaching staff. As shown in Table1, an example of such an implementation is when students acquire their coursework in its entirety, during the third or fourth year, by means of PBL. This would undoubtedly require a major revamp of the curriculum, along with realignment of program's objectives and outcomes. At the macro level, certain courses in the curriculum are designated to be taught utilizing PBL, irrespective of who is in charge of the course. A macro implementation requires departmental approval and a firm commitment by the instructors teaching the course. Courses offered in multiple sections require coordination between instructors. The micro-level approach requires the least amount of resources. Its implementation is flexible, non-binding and amendable. This is where PBL can be used on a trial basis for certain topics in a selected course(s) within a certain time limit. Hence, this approach is highly recommended for trying out PBL for the first time.

C. The Start up of PBL: A gradual, step at a time approach, should be taken when infusing PBL in a program. At the start, steps should be taken to raise awareness and educate instructors and students on key issues, techniques and potential hurdles that may arise when using PBL for the first time. During this initial period, it is advisable to form a central committee from experienced or semi-experienced lecturers, who are at ease with active learning strategies in general and PBL in particular; to facilitate the promotion of PBL at all levels of the academic community. This is a challenging time that requires patience, persistence, and social skills on the part of the committee members entrusted with the task of embarking on the process- where the committee will be moving against the tide in trying to plant the initial seeds of change. The major tasks that would be undertaken at this stage are: to introduce PBL gradually and properly, to convince teachers and students of its merits, and to help train potential lecturers of when and how to use PBL. As instructors gain familiarity with PBL, they begin to develop their own techniques. Listening to students can give instructors direction and insight into how well students understand concepts and material being taught.

\section{Student Engagement Using Cooperative Learning Structures: A Priority to PBL}

As noted earlier, relying solely on the traditional lecture approach, no matter how competent the lecturer is, fails to engage students in learning, thus indirectly depriving students of learning experiences and opportunities that could only materialize utilizing engagement strategies. 


\begin{tabular}{|l|l|ll|}
\hline \multicolumn{1}{|c|}{ Level } & \multicolumn{1}{|c|}{ Range of Application } & \multicolumn{1}{c|}{ Details } \\
\hline Mega Level & $\begin{array}{l}\text { PBL is applied to the entire 3rd or 4th } \\
\text { year of a selected program }\end{array}$ & $\begin{array}{l}\text { Major revamp of curriculum } \\
\text { Needed commitment at all levels }\end{array}$ \\
\hline $\begin{array}{l}\text { Macro } \\
\text { Level }\end{array}$ & $\begin{array}{l}\text { PBL applied to two or three subjects } \\
\text { in the 3rd or 4th year of a selected } \\
\text { program }\end{array}$ & $\begin{array}{l}\text { Need departmental approval and } \\
\text { firm commitment from the } \\
\text { lecturers teaching the selected } \\
\text { subjects }\end{array}$ \\
\hline $\begin{array}{l}\text { Micro } \\
\text { Level }\end{array}$ & $\begin{array}{l}\text { PBL is applied to specific topics in a } \\
\text { selected one or two courses }\end{array}$ & $\begin{array}{l}\text { Recommended for new starters } \\
\text { Will require proper coordination } \\
\text { when implemented in courses } \\
\text { with multi sections }\end{array}$ \\
\hline
\end{tabular}

\section{Table 1. Different approaches of infusing PBL}

Under the umbrella of engagement strategies, there are numerous models available to select from, including the models predicated on cooperation - working together to accomplish shared goals. Within cooperative strategies, individuals seek outcomes that are beneficial to themselves and beneficial to all group members within the class. ${ }^{(2,10)}$ The work by Johnson, Johnson, and Smith ${ }^{(2,10)}$ reveals that students exhibit a higher level of individual achievement, develop more positive interpersonal relationships, and achieve greater levels of academic self-esteem when participating in a successful cooperative learning environment.

Cooperative learning researchers and practitioners have shown that positive peer relations are essential to success in college. The positive interpersonal relationships promoted through cooperative learning are regarded by most as crucial to today's learning communities. The underlying precept of cooperative and problem-based learning is “interdependence”.

Cooperation is more than being physically near other students. It is actually a state of mind. A willingness to open up to others, exchange information and views with others, and accept the fact that working together is more beneficial to all involved in the exercise. For a cooperative learning experience to be successful, it is imperative that the following be integrated into the class activity: ${ }^{3,22,23)}$

- Positive Interdependence- Students should perceive that they need each other to complete the planned activity.

- Face to Face Interaction- Students should work together in planning, executing, and arriving at conclusions. They should share the work load, and share the credit. Thus promoting each others learning.

- Accountability- Each student's role and performance is to be assessed, and the results are those of the group (and for the group). Keeping track of the contribution and knowledge gained by each member could be monitored, as well, by either testing each and every student in the group, or by randomly selecting a group member (or members) to be tested and thus proxy for the group.

- Sharing known skills- Students who possess certain skills (examples: computer skills, laboratory skills, data reduction skills, presentation skills) should be willing to pass it on, and/or share it with their group members. 
- Collaborative Skills- Groups cannot function effectively if members do not have (be willing to learn) or use some needed social skills. These skills include leadership, decision making, trust building, and conflict management.

- Monitoring Progress- Groups need to discuss amongst themselves whether they are achieving their set goals; they also need to prioritize the scheduled activities, introduce changes if need be, solicit advice and assistance with the consent of the instructor, and maintain effective working relationships among the members.

Success in implementing problem-based cooperative learning is attributable, in large measure, to: proper planning, efforts, dedication, and foresight of the instructor. Experience definitely is a major factor. A proper start for instructors wanting to try any of the active learning strategies for the first time (including problem-based cooperative learning) is to step into it gradually, and to seek continuous feedback as to how the course is going and how the students feel about it. In addition, he /she can tap into available documented sources, attend seminars /workshops on the subject matter, and discuss planned activities for his /her course with experienced colleagues who can offer constructive comments and advise.

\section{The Lecture Format together with Active Learning Strategies}

When asked why he lectures, one faculty responded: "It is tradition. It was part of my training, and seems to dwell in me and seems like what I should be doing. I feel guilty when I am not lecturing." (24) This candid statement suggests one of the great dilemmas faced by all who teach at the postsecondary level. Lecturing is virtually synonymous with teaching. It was the dominant method by which we were taught - and it is the method by which most of us teach. When discussing potential change in current teaching-learning strategies, many faculty members become defensive, and discussions may quickly degenerate into heated debates where sides are clearly drawn. Over-exuberant advocates of active learning have, unfortunately, not been able to persuade the majority of those who have grown accustomed to traditional teaching methods. More efforts and better approaches in persuading the traditionalists appear necessary. Better is an alternative approach that recognizes that one's choice of an instructional method is best viewed as appropriate or inappropriate only when placed within the context that considers the instructor's specific objectives, the complexity of the subject matter, the physical setting of the classroom, and the capabilities of the learners. The challenge is to choose a suitable method at the appropriate time. Understanding the pros and cons of the lecture method is a helpful start.

Lectures have a number of characteristics that does make them, for the right subject matter, desirable in the classroom ${ }^{(24)}$. It does, to a great extent, depend on the abilities and experience of the lecturer. An able and committed lecturer can accomplish the following:

1. Relate the material proficiently and effectively, in a manner that reflects lecturer's personal conviction and grasp of the subject matter;

2. Provide students with a thoughtful, scholarly role model to emulate;

3. Supplement the subject matter with current developments not yet published, or interject lecturer's own views derived from his /her own experience whenever applicable;

4. Organize material in ways to meet the particular needs of a given audience;

5. Efficiently deliver large amounts of information when the need arises without confusing his /her audience; 
6. Underscore key points, simplify complexities, illustrate with facts and figures, and arrive at well "thought-out" conclusions.

In addition, lectures are presumably cost-effective in that they can reach many listeners at one time. They present a minimum threat to students in that they are not required to actively participate, and they provide an advantage for those students who find learning by listening enjoyable. ${ }^{(24)}$ As most students will attest, not all lectures or lecturers achieve these goals. Research findings suggest that a number of identifiable attributes must be implemented to make a lecture truly effective. For instance, students remember material presented at the beginning of a lecture better than information presented in the middle or at the end of the lecture. Also, the effectiveness of the lecture varies inversely with the difficulty of the material presented, and listeners retain factual material better when presented in short sentences rather than in long sentences. Speaking extemporaneously is more effective than reading from lecture notes, and it is desirable to change the pitch, intensity, and timbre of one's voice. ${ }^{(25)}$ These characteristics presume that the lecturer is an enthusiastic and knowledgeable scholar. But, we realize that most campuses have a few that fit this description, and can be labeled as gifted practitioners who could keep most students interested during the formal 50- minute lecture. Even if it is assumed that most engineering lecturers possess these necessary characteristics, research has shown that the exclusive use of the lecture in the classroom constrains students' learning.

One of the most important problems associated with total reliance on the lecture method is the inability of most students to listen effectively to any lecturer, no matter how skillful, over a sustained period. Research on the learning experiences of college students exposed to straight lecturing found that after an initial settling-in period of a few minutes, students readily assimilated materials for the next five minutes or so. Ten to twenty minutes into the lecture, however, confusion and boredom set in and assimilation fell rapidly, remaining at a low state until a brief period toward the end of the session when students were revived by the knowledge that the lecture would soon be over. ${ }^{(26)}$ There are too many reports in the literature on lack of concentration by the audience, even when the lecturer is brilliant and the attendees are highly motivated, including medical students. ${ }^{(27)}$ When it comes to "note-taking" during a 50 minute lecture, research has shown that students have noted 40 percent of the content presented during the first 15 minutes, 25 percent of the total content in a 30 minute-period, and only 20 percent during 45 minutes. ${ }^{(26)}$ Research also suggests that the relative effectiveness of a lecture depends on the educational level of the audience. "In general, very little of a lecture can be recalled except in the case of listeners with above average education and intelligence." (25) Even with bright, competent students listening to an interesting topic presented by a knowledgeable speaker, several serious problems remain, including the following:

1. Course content is often presented via lecture in unorganized and uneven fashion. This makes it difficult for students to determine the most important aspects of the lecture (i.e., what's going to be on the exam?);

2. Many college students do not know how to take effective notes. Although various strategies and formats for effective "note-taking" have been identified. The fact is that "note-taking" is seldom taught;

3. The listening, language, and /or motor skill deficits of some students make it difficult for them to identify important lecture content and write it down correctly and quickly enough during a lecture; 
4. Instructors sometimes get off-track from the primary objectives of the lecture. Professorsespecially those who really know and love their disciplines - are famous for going off on tangents during lecture. Although getting off-track would break the monotony, it could make it difficult for even the most skilled note-takers to determine the most important content.

For those instructors who would like to go beyond the traditional methods of lecturing, a number of effective strategies promoting active learning are available to choose from. ${ }^{(3,4,5)}$ If a faculty member is hesitant about selecting one or more of these active learning strategies because some questions exist about its comparative effectiveness with the lecture method, he or she should consider the following: research has shown, beyond the shadow of doubt, that these strategies do deliver content as well as lectures while providing diverse presentations that enhances students' motivation and achievement, and helps in building up desirable personal traits. ${ }^{(17,19,26)}$

\section{Concluding Remarks}

On the whole, the intended move towards encouraging instructors to adopt problem-based learning (PBL) seems farfetched and difficult to accomplish, especially in the initial stage. This is because time is needed for those undertaking the task to be trained to implement and gain the experience necessary to move the process forward. Time is also needed for other stakeholders to be convinced and provide the support needed to prescribe the change. Most importantly, those promoting the change must be able to show evidence that PBL is effective for engineering education.

It is highly recommended that an Active Learning Taskforce be formed of experienced faculty, to initiate, infuse, and oversee the progress made. Their determination, patience, and resilience are required to successfully promote college-wide implementation of PBL. Nevertheless, with clear intention, goals and plans of action, coupled with support from the highest level of the University's key personnel, the Taskforce and other core groups, should be able to move the

process forward. Success would almost be guaranteed, when a well-coordinated University-wide implementation of PBL is underway in other colleges of the University.

\section{Bibliography}

1. Christensen, C.R., Garvin, D.A., and Sweet, A., "Education for Judgment: The Artistry of Discussion Leadership”, Cambridge, Mass.: Harvard Business School, 1991.

2. Smith, K.A., Sheppard, S.D., Johnson, D.W., and Johnson, R.T., "Pedagogies of Engagement: ClassroomBased Practices,” ASEE Journal of Engineering Education, vol. 94, no.1, 2005, pp.87 -102.

3. Prince, M., "Does Active Learning Work? A Review of the Research," ASEE Journal of Engineering Education, vol. 93, no.3, 2004, pp.223-231

4. Prince, M., and Felder, R.M., "Inductive Teaching and Learning Methods: Definitions, Comparisons and Research Bases,” ASEE Journal of Engineering Education, vol.95, no.2, 2006, pp.123-138.

5. Randolph, G.B., "Collaborative Learning in the Classroom: Writing Across the Curriculum Approach.” Journal of Engineering Education, vol.89, no.2, April 2000, pp.119-122.

6. Bloom, B.S., Taxonomy of Educational Objectives: The Classification of Educational Goals by a Committee of College and University Examiners, McKay Co., Inc., New York, NY, 1956, pp.189-193. 
7. Kolb, D.A., "Experiential Learning: Experience as the Source of Learning and Development," Prentice Hall, Englewood Cliffs, CA, 1984

8. Frederick, Peter J., "Student Involvement: Active Learning in Large Classes," In Teaching Large Classes Well, edited by M.G.Weimer. New Directions for Teaching \& Learning no.32, Jossey-Bass, San Francisco, Ca, 1987.

9. Millis, B., and Cottell Jr. P., “Cooperative Learning for Higher Education Faculty,” American Council on Education, ORYX Press, 1998.

10. Johnson, D.W., Johnson, R.T., and Smith, K.A., Cooperative Learning: Increasing College Faculty Instructional Productivity, ASHE-ERIC Report on Higher Education, Washington, D.C.: The George Washington Univ., 1991.

11. Springer, L., M. Stanne, and S. Donavan, "Effects of Small-Group Learning on Undergraduates in Science, Mathematics, Engineering, and Technology: A Meta-Analysis," Review of Educational Research, vol.69, no.1, 1999, pp.21-52.

12. Wales, Charles E., and Robert A. Stager, The Guided Design Approach, Educational Technology Publications, Englewood Cliffs, N.J., 1978.

13. Mourtos, N.J., "The Nuts and Bolts of Cooperative learning in Engineering," Journal of Engineering Education, vol. 86, no.1, 1997, pp.35-37.

14. Mayo, P., M.B.Donnelly, P.P.Nash, \& Schwartz, R. W., "Student Perceptions of Tutor Effectiveness in Problem Based Surgery Clerkship,” Teaching and Learning in Medicine vol.5, no.4, 1993, pp. 227-233.

15. < $<$ http://www.ntlf.com/html/pi/9812/toc.html>, accessed 12/12/08.

16. Barrows, H.S., and Tamblyn, R. N. Problem-Based Learning: An Approach to Medical Education, New York, N.Y., Springer, 1980.

17. Barrows, H. S., "Problem -Based Learning in Medicine and Beyond: A Overview," in Wilkerson, L. and W.H. Gijselaers, eds., New Directions for Teaching and Learning, no. 68,pp.3-11, San Francisco, Cal.: Jossey-Bass Publishers, 1996,

18. Woods, D.R., Problem -Based Learning: How to Gain the Most from PBL, Waterdown, Ontario: Donald R. Woods, 1994.

19. Allen, D. E., Duch, B. J., and Groh, S. E., "The Power of Problem-Based Learning in Teaching Introductory Science Courses," in Wilkerson, L. and W.H. Gijselaers, eds., New Directions for Teaching and Learning, No. 68, pp.3-11, San Francisco, Cal.: Jossey-Bass Publishers, 1996.

20. Tan, O.S., Problem-Based Learning Innovation: Using Problems to Power Learning in the 21st Century. Singapore: Thomson Learning, , 2003.

21. Johnson, D.W., Johnson, R.T., and Smith, K.A., Active Learning: Cooperation in the College Classroom, 2nd ed., Edina, MN: Interaction Book Company, 1998.

22. McLeod, A., "Discovery and Facilitating Deep Learning States," National Teaching and Learning Forum, Vol.5, no.6, 1996, pp.1-7

23. Lowman, Joseph, Mastering the Technique of Teaching, Jossey- Bass, San Francisco, Ca. 1984.

24. Creed, Thomas, "Why We Lecture," Symposium: A Saint John's Faculty Journal, no.5: 1986: pp. 17-23.

25. Verner, C.and G. Dickinson, "The Lecture: An Analysis and Review of Research,” Adult Education, no. 17, 1967, pp.85-100.

26. Penner, Jon, G., Why Many College Teachers Cannot Lecture. Charles C. Thomas, Springfield, Ill., 1984.

27. Bonwell, C.C., and J.A. Eison, “Active Learning: Creating Excitement in the Classroom,” ASHE-ERIC Higher Education Report No.1, George Washington University, Washington, DC, 1991 